\title{
Left ventricular hypertrophy
}

\author{
An underappreciated coronary risk factor
}

Left ventricular hypertrophy is often assumed to be little more than a marker for hypertension. In fact, the relation between diastolic or systolic blood pressure and left ventricular mass is not always close. ${ }^{12}$ Left ventricular hypertrophy is an independent risk factor for myocardial infarction and death in men and women with hypertension ${ }^{34}$ and in asymptomatic subjects with normal blood. ${ }^{56}$ In hypertensive patients it is a stronger coronary risk factor than casual blood pressure readings.

Early data from the Framingham study showed that patients with ST-T repolarisation abnormalities ("strain") on the electrocardiogram had a sixfold increase in cardiac deaths over a 20 year follow up period. ${ }^{7}$ Echocardiography, however, is $5-10$ times more sensitive than the electrocardiogram and detects left ventricular hypertrophy in $25-30 \%$ of all hypertensive patients. ${ }^{2}$ In such patients, myocardial infarction or death occurs at the rate of 4.6 events per 100 patient years, three times the risk in patients with hypertension and normal left ventricular mass. ${ }^{3}$ Women are not spared this increased risk. ${ }^{4}$ Even in asymptomatic subjects with normal blood pressure, increased left ventricular mass emerges as a risk factor for coronary disease, cardiac death, and all cause mortality.$^{6}$ The relative risk of all cause mortality is 1.5 in men and 2.0 in women for every $50 \mathrm{~g} / \mathrm{m}$ increment in left ventricular mass indexed to height. The relative risk of sudden death is 1.7 per $50 \mathrm{~g} / \mathrm{m}$ increment.

In all these studies multivariate analysis shows that, as a risk factor, left ventricular hypertrophy is independent of systolic and diastolic blood pressure, smoking, and cholesterol concentrations. ${ }^{3-6}$ It is not always independent of age..$^{46}$ The relation between left ventricular mass and established coronary artery disease has also been examined in black subjects: left ventricular hypertrophy with normal coronary anatomy was associated with a five year mortality of $16 \cdot 1 \%$, which was similar to the mortality $(17 \cdot 6 \%)$ with multivessel disease and normal left ventricular mass. Left ventricular hypertrophy was a more important independent predictor of death than multivessel disease or impaired left ventricular systolic function. ${ }^{8}$ Other studies have shown a similar effect on the risk of death and reinfarction after $Q$ wave ${ }^{9}$ or non- $Q$ wave infarction. ${ }^{10}$

Care must be taken when applying the results of these studies to individual patients. In routine clinical practice, left ventricular hypertrophy is usually defined by increased wall thickness, while research studies have used $M$ mode echo- cardiography to estimate left ventricular mass with a formula incorporating septal and posterior wall thickness and diastolic cavity diameter. ${ }^{11}$ This calculation is then indexed either to height or to body surface area and a threshold for hypertrophy determined by using a control population.

Definitions of left ventricular hypertrophy have varied and normotensive control subjects may have an incidence from $1 \cdot 3 \%$ to $9 \cdot 4 \%$ according to which one of 13 criteria is applied. ${ }^{2}$ For research purposes it is probably better to treat left ventricular mass as a continuous variable without categorising it as either normal or abnormal; in clinical use, thresholds for hypertrophy of $134 \mathrm{~g} / \mathrm{m}^{2}$ in men and $110 \mathrm{~g} / \mathrm{m}^{2}$ in women seem reasonable. ${ }^{2}$ However, even these may vary with population characteristics such as age, race, and physical activity, so that matched contemporaneous control groups should ideally be used. Furthermore, $M$ mode tends to overestimate left ventricular mass, and two dimensional methods are more accurate, particularly when cavity size or myocardial thickness is non-uniform..$^{12}$ Generalisation to the whole left ventricle from $\mathrm{M}$ mode dimensions recorded at the base of the heart is inappropriate in the presence of established infarction; this diminishes the importance of some studies. ${ }^{8}$

What explains the association between left ventricular hypertrophy and increased risk? Although left ventricular mass may correlate poorly with casual systolic blood pressure and even less well with diastolic blood pressure, ${ }^{12}$ it is better related to 24 hour $^{13}$ or 30 year history of blood pressure. ${ }^{14}$ Therefore, increased left ventricular mass could still be a marker for end organ effects of long term hypertension. Left ventricular hypertrophy, however, is also known to be determined by other factors that may possibly increase coronary risk - these include obesity, age, blood viscosity, salt intake, ${ }^{12}$ and various genetically determined influences. The dd genotype of the angiotensin converting enzyme gene is linked with left ventricular hypertrophy but not with hypertension and has been shown to carry a higher risk of fatal and non-fatal myocardial infarction than the ii genotype in some $^{1516}$ but not all studies. ${ }^{17}$ Left ventricular hypertrophy may also occasionally develop as a result of established coronary disease as repeated ischaemia in dogs can induce left ventricular hypertrophy. ${ }^{18}$

Left ventricular mass may itself contribute to coronary risk through increased oxygen demand and reduced coronary reserve, impaired endocardial autoregulation, and possibly 
small vessel disease. ${ }^{19}$ Finally, increased left ventricular mass may result not only from cell hypertrophy but also from increases in collagen, which may provide a substrate for malignant arrhythmias and sudden death..$^{20}$

Given the prognostic importance of left ventricular hypertrophy it seems appropriate to look for it in every patient at risk. As left ventricular mass is not closely related to casual blood pressure readings, we need to investigate patients with borderline as well as unequivocal hypertension.

Several management options exist when left ventricular hypertrophy is detected. We might apply the same aggressive treatment of coronary risk factors as after documented infarction because the risk of future cardiac events is about the same. We could initiate earlier investigation of such patients with routine nuclear imaging or stress echocardiography. Once it is found, we might treat coronary disease more aggressively than usual as even single vessel disease more than doubles mortality if associated with left ventricular hypertrophy. ${ }^{8}$ Or we could aim for regression of left ventricular hypertrophy as well as blood pressure control by choosing angiotensin converting enzyme inhibitors, nondihydropyridine calcium channel $B$ blockers, or blockers without intrinsic sympathomimetic activity. In patients with borderline hypertension, left ventricular hypertrophy argues the need for treatment.

Although all these approaches are intuitively sensible, and unlikely to do harm, none has yet been tested in this group of patients. We need research to guide management in these patients, but until the results are available it seems sensible to use left ventricular hypertrophy as a cue for tighter risk factor management, blood pressure control, and investigation for coexistent coronary artery disease.

JOHN CHAMBERS Senior lecturer in cardiology

Guy's Hospital,

London SE1 9RT
1 Savage DD, Drayer J, Henry WL, Matthews EC, Ware JH, Gardin JM, et al. Echocardiographic assessment of cardiac anatomy and function in hypertensive subjects. Circulation 1979;64: 623-31.

2 Hammond IW, Devereux RB, Alderman MH, Lutas EM, Spitzer MC, Crowley JS, et al. The prevalence and correlates of echocardiographic left ventricular hypertrophy among employed prevalence and correnta

3 Casale PN, Devereux RB, Milner M, Zullo G, Harshfield GA, Pickering T, et al. Value of echocardiographic measurement of left ventricular mass in predicting cardiovascular morbid echocardiographic measurement of left ventricular mass in

4 Koren MJ, Devereux RB, Casale PN, Savage DD, Laragh JH. Relation of left ventricular mass and geometry to morbidity and mortality in uncomplicated essential hypertension. Ann Intern Med 1991;114:345-52.

5 Levy D, Garrison RJ, Savage DD, Kannel WB, Castelli WP. Left ventricular mass and incidence of coronary heart disease in an elderly cohort. The Framingham study. Ann Intern Med 1989;110:101-7.

6 Levy D, Garrison RJ, Savage DD, Kannel WB, Castelli WP. Prognostic implications of echocardiographically determined left ventricular mass in the Framingham heart study. $N$ Engl fMed 1990;322:1561-6.

7 Kannel WB. Prevalence and natural history of electrocardiographic left ventricular hypertrophy. Am F Med 1983;(suppl 3A):4-11.

8 Liao Y, Cooper RS, McGee DL, Mensah GA, Ghali JK. The relative effects of left ventricular hypertrophy, coronary artery disease, and left ventricular dysfunction on survival among black adults. $¥ A M A$ 1995;273:1592-7.

9 Bolognese L, Dellavesa P, Rossi L, Sarasso G, Bongo AS, Scianaro M. Prognostic value of left ventricular mass in uncomplicated acute myocardial infarction and one-vessel coronary artery disease. Am $\mathcal{F}$ Cardiol 1994;73:1-5.

10 Boden WE, Kleiger RE, Schechtman KB, Capone RJ, Schwartz DJ, Gibson RS. Clinical significance and prognostic importance of left ventricular hypertrophy in non- $Q$ wave acute myocardial infarction. Am $\mathcal{F}$ Cardiol 1988;62:1000-4.

11 Devereux RB, Reichek NR. Echocardiographic determination of left ventricular mass in man anatomic validation of the method. Circulation 1977;55:613-8.

12 Reichek N, Helak J, Plappert T, St John Sutton M, Weber KT. Anatomic validation of lef ventricular mass estimates from clinical two-dimensional echocardiography: initial results. Circulation 1983;67:348-52.

13 Rowlands DB, Glover DR, Ireland MA, McLeay RAB, Stallard TJ, Watson RDS, et al. Assessment of left-ventricular mass and its response to antihypertensive treatment. Lancet 1987;: :467-70.

14 Lauer MS, Anderson KM, Levy D. Influence of contemporary versus 30-year blood pressure levels on left ventricular mass and geometry: the Framingham heart study. $f \mathrm{Am}$ Coll Cardiol 1991;18:1287-94.

15 Evans AE, Poirier O, Kee F, Lecerf L, McCrum E, Falconer T, et al. Polymorphisms of the angiotensin-converting-enzyme gene in subjects who died from coronary heart disease. $Q \mathcal{f} \mathrm{Med}$ 1994;87:211-4

16 Cambien F, Poirier O, Lecerf L, Evans A, Cambou J-P, Arveiler D, et al. Deletion polymorphism in the angiotensin converting enzyme gene is a potent risk factor for myocardial infarction Nature 1992;359:641-4.

17 Katsuya T, Koike G, Yee TW, Sharpe N, Jackson R, Norton R, et al. Association of angiotensinogen gene T235 variant with increased risk of coronary heart disease. Lancet 1995;345:1600-3.

18 Fujita M, Mikuniya A, McKown DP, McKown MD, Franklin D. Regional myocardial volume alterations induced by brief repeated coronary occlusion in conscious dogs. $\mathcal{F}$ Am. Coll Cardiol 1988:12:1048-53.

19 Harrison DG, Marcus ML, Dellsperger KC, Lamping KG, Tomanek RJ. Pathophysiology of myocardial perfusion in hypertension. Circulation 1991;83(suppl III):III14-8.

20 McLenachan JM, Henderson E, Morris KI, Dargie HJ. Ventricular arrhythmias in patients with hypertensive left ventricular hypertrophy. N Engl f Med 1987;317:787-92.

\section{What's happening to nursing?}

\section{The traditional division of labour between nurses and doctors is changing}

British nursing has notched up many successes in the past decade. Nursing practice, underpinned by radical reform of nursing education, has shifted from a task centred approach towards personalised care; other innovations have improved the quality of care; and research and critical thinking are flourishing. It is an impressive record.

Against this backdrop, understanding why Christine Hancock, that most lucid and reasonable of union leaders, should find herself leading the Royal College of Nursing in an assault on the government may be difficult. Yet, far from feeling buoyed up by their recent achievements, nurses are experiencing what Carpenter calls "a much deeper sense of betrayal than the difference between $1 \%$ and $3 \%$ in pay (p 338)." Something has gone badly wrong. While nurses' concern over pay is real, it has also acted as a trigger for their discontent over the state of the profession and the state of the NHS itself.

This week's articles on nursing provide clues to understanding this paradox (pp 338, 303, 309).$^{1-3}$ Many of the issues are not new: Davies's important new book (reviewed by Carpenter ${ }^{1}$ echoes some of the conclusions of earlier analyses. ${ }^{5}$ The central predicament of nursing as a woman's occupation in a man's world remains unresolved, while the traditional marginalisation of nursing by medicine and governments continues. These chronic problems have been compounded by the new market culture of the NHS, which leaves nurses wondering whether altruism, compassion, and social justice -the values nursing espouses at its best-have any place in the new world of balance sheets and short term contracts.

The marginalisation not only of nursing but of the values it traditionally represents underlies the confusion and grief felt by many doctors and nurses. Bradshaw and Short, from different perspectives, deplore the apparent demise of tender loving care. ${ }^{2}$ Their reasoning may be shaky and imbued with nostalgia for a mythical golden age, but many share their feelings. In particular, nurses are desperately trying to maintain their traditional values while finding a place in the new order, in which they are still relatively powerless. This struggle creates dilemmas that epitomise the tensions arising from unpopular NHS reforms.

Nursing work is undervalued partly because of doctors' ignorance about it. 'Twas ever thus, but the rules of the game are changing. ${ }^{6}$ Today's nurses are increasingly likely to be assertive and well educated, while the doctors who symbolise 